\title{
Immunohistological diagnosis of central nervous system tumours using a monoclonal antibody panel
}

\author{
HUGH B COAKHAM, $\dagger$ JEREMY A GARSON, $\ddagger$ PATRICIA M ALLAN, ${ }^{*}$ \\ EDNA I HARPER, ${ }^{*}$ BETTY BROWNELL, $\ddagger$ JOHN T KEMSHEAD, E BIRGITTE LANE ${ }^{\prime}$
}

From the *Brain Tumour Research Laboratory, †Departments of Neurosurgery and $\ddagger$ Neuropathology, Frenchay Hospital, Bristol, and the \$Imperial Cancer Research Fund Oncology Laboratory, Institute of Child Health, London, and "Lincoln's Inn Fields, London

SUMMARY A panel of seven monoclonal antibodies has been used to characterise 164 cerebral and spinal tumours. These reagents have enabled rapid and accurate diagnosis of tumours to be made, particularly in cases where standard techniques have proved equivocal. On the basis of characteristic antigenic profiles of tumours, it has been possible to distinguish between gliomas, meningiomas, schwannomas, medulloblastomas, neuroblastomas, choroid plexus tumours, various metastatic deposits, and primary brain lymphomas. The reagents used in the study comprise antibodies binding to $(a)$ most neuroectodermally derived tissues and tumours (UJ13A), (b) fetal brain and tumours of neuroblastic origin (UJ181.4), (c) schwannomas, normal and neoplastic neurones (UJ127.11), $(d)$ glial cells (FD19), $(e)$ epithelial cells (LE61), and $(f)$ leucocytes (2D1).

Some reagents, such as antibody $\mathrm{A}_{2} \mathrm{~B}_{5}$, were less effective as diagnostic markers than originally suggested by previously described specificity. This monoclonal antibody reacted with both neuroectodermal and epithelial derived tumours. The panel of monoclonal antibodies was most useful in the diagnosis of tumours composed of small round cells, particularly lymphoma and neuroblastoma, but the pattern of reactivities allowed most of the central nervous system tumours to be accurately classified. This approach was a valuable adjunct to conventional histological techniques in about $20 \%$ of the cases examined.

Although most cerebral tumours can be diagnosed by the use of conventional histological staining techniques, there remains a substantial proportion in which the diagnosis remains uncertain and other investigations, such as electron microscopy, are necessary. The monoclonal antibody technique provides reagents that are specific and reproducible, which makes them ideal markers for immunocytochemistry. ${ }^{23}$

In this study 50 monoclonal antibodies were initially screened on a wide range of normal and neoplastic tissues, using either indirect immunofluorescence or immunoperoxidase techniques. ${ }^{4}$ Seven of these were selected on the basis of diagnostic potential: binding to neuroectodermally derived tissues, glial cells, neuronal cells, epithelial cells, and cells of lymphoid origin. The antibodies were used as a panel in a prospective study of 164 cranial and spinal tumours in order to establish the consistency of

Accepted for publication 4 October 1984 reaction patterns and their diagnostic capability when compared with classical neuropathological techniques.

In certain cases additional antibodies were used to refine diagnosis by achieving fuller characterisation of cells. The main purpose of the study, however, was to evaluate the diagnostic power of a preselected panel of markers when used routinely as an adjunct to conventional histological techniques.

\section{Material and methods}

\section{MONOCLONAL ANTIBODIES}

The seven antibodies selected for this study are listed in Table 1 together with reference to their origin. FD19 was raised after immunisation of mice with homogenised human cerebellar astrocytoma (grade I), and UJ13A, UJ127.11, and UJ181.4 were raised by immunisation of $\mathrm{Balb} / \mathrm{C}$ mice with human fetal brain. Spleen cells were fused with the mouse myeloma cell line P3-X63-Ag8-653 using polyethylene glycol. The precise specificities of these 
Table 1 Monoclonal antibody panel used in central nervous system tumour diagnosis

\begin{tabular}{|c|c|c|c|c|}
\hline Antibody & Immunogen & Antigen & Tissue distribution & Reference \\
\hline $\begin{array}{l}\text { UJ13A } \\
\text { UJ127.11 }\end{array}$ & $\begin{array}{l}16 \text { wk fetal brain } \\
16 \text { wk fetal brain }\end{array}$ & $\begin{array}{l}\text { Membrane* } \\
\text { Membrane glycoprotein } \\
\text { MW } 220000\end{array}$ & $\begin{array}{l}\text { Normal and neoplastic neuroectoderm } \\
\text { Neuroblastic tissues and tumours; also } \\
\text { schwannomas }\end{array}$ & $\begin{array}{l}2 \\
3\end{array}$ \\
\hline $\begin{array}{l}\text { UJ181.4 } \\
\text { FD19 }\end{array}$ & $\begin{array}{l}16 \text { wk fetal brain } \\
\text { Astrocytoma }\end{array}$ & $\begin{array}{l}\text { Membrane* } \\
\text { Glial fibrillary acidic }\end{array}$ & $\begin{array}{l}\text { Neuroblastic tumours } \\
\text { Astrocytes and astrocytic tumours }\end{array}$ & $\begin{array}{l}4 \\
4\end{array}$ \\
\hline LE61 & Epithelial cells & $\begin{array}{l}\text { Cytoplasmic cytokeratin } \\
\text { MW } 45000\end{array}$ & Simple epithelium and carcinomas & 5 \\
\hline 2D1 & $\begin{array}{l}\text { Mononuclear } \\
\text { leucocytes }\end{array}$ & $\begin{array}{l}\text { Membrane } \\
\text { MW } 220000\end{array}$ & Leucocytes lymphomas & 6 \\
\hline$A_{2} B_{5}$ & $\begin{array}{l}\text { Chick retinal cell } \\
\text { culture }\end{array}$ & $\begin{array}{l}\text { Membrane } \\
\text { GQ ganglioside }\end{array}$ & Normal and neoplastic neuroectoderm $\dagger$ & 7 \\
\hline
\end{tabular}

*Molecular weight unknown.

$\dagger A_{3} B_{5}$ was originally described as a neuronal marker but reacts broadly with neuroectoderm and also stratified squamous epithelium and a variety of carcinomas.

antibodies have been determined on frozen sections of a large range of normal and malignant tissues.

\section{TUMOURS}

Fresh operative samples, obtained from the Department of Neurosurgery, Frenchay Hospital, Bristol, were snap frozen in liquid nitrogen and stored at $-70^{\circ} \mathrm{C}$. Dr Gill Cole kindly provided a number of tumours, which were similarly frozen and transported from the Department of Neuropathology, University Hospital of Wales, Cardiff.

\section{INDIRECT IMMUNOFLUORESCENCE AND \\ IMMUNOPEROXIDASE TECHNIQUES}

Six micron thick, unfixed frozen sections on gelatin coated glass slides were hydrated for $5 \mathrm{~min}$ in Dulbecco A (Oxoid Ltd) phosphate buffered saline with calcium and magnesium (PBS). Excess PBS was removed from the sections and $50 \mu l$ of appropriately diluted* monoclonal antibody was added. The sections were then incubated in a humid chamber for $30 \mathrm{~min}$ at room temperature. After two washes ( 5 min each in PBS), sections were similarly incubated with $50 \mu \mathrm{l}$ of fluorescein conjugated goat antimouse immunoglobulin (affinity purified conjugate supplied by $\mathrm{J}$ Kemshead, ICRF, used at $1 / 80$ dilution) for $30 \mathrm{~min}$, washed as before, and then mounted under coverslips using $90 \%$ glycerol and $10 \%$ PBS. Sections were examined at $\times 400$ magnification using a Zeiss Standard 14 microscope fitted with an IV FL epi-fluorescence condenser.

For immunoperoxidase studies the fluorescent antibody was replaced with an affinity purified rabbit antimouse peroxidase conjugate used at a dilution of $1 / 20$ (Dakopatts Ltd, cat no P260). Antibody binding was visualised by a further 10 min incuba-

\footnotetext{
* Monoclonal antibodies were made up in PBS containing 5\% fetal calf serum and used at the following dilutions. FD19 ascites at 1/500; UJ13A ascites at 1/1000; UJ127.11 ascites at 1/200; UJ181.4 ascites at 1/400; LE61 supernatant at 1/10; 2Dl supernatant undiluted; $A_{2} B_{5}$ (Sera Lab Ltd, cat no MASO45c) at $1 / 50$ and BE4 ascites at $1 / 4000$.
}

tion with diaminobenzidene $0.5 \mathrm{mg} / \mathrm{ml}$ in $0.2 \mathrm{M}$ Tris buffered saline plus $0.01 \%$ hydrogen peroxide. Slides were washed (three times for 5 min each in Tris buffered saline) and lightly counterstained with $10 \%$ Harris' haematoxylin. The sections were gently dehydrated through alcohols (beginning with $30 \%$ ) to ensure the minimum disruption of the unfixed sections, cleared in two changes of xylene, and mounted in DPX or Permount.

The antibody panel was tested synchronously on compound sections consisting of three or four tumours. Antibody BE4 (antinuclear histone: Dr B Anderton, St George's Medical School, London) was used as a positive control and non-immune ascites as a negative control. Haematoxylin and eosin preparations were used to aid the orientation and interpretation of the immunfluorescence slides.

\section{Results}

The results show that gliomas of all types express the pan-neuroectodermal UJ13A antigen and contain variable amounts of glial fibrillary acidic protein as detected by antibody FD19 (Table 2). The glial fibrillary acidic protein expression is greatest in astrocytomas, with smaller amounts being found in highly malignant gliomas and also in oligodendrogliomas. This is consistent with the findings of van der Meulen et al ${ }^{\varphi}$ and Velasco et $a l,{ }^{10}$ who used glial fibrillary acidic protein antiserum. Weak staining by the neuroblastic cell marker UJ181.4 was seen in $5 / 31$ malignant gliomas and 3/6 oligodendrogliomas.

The various categories of glioma cannot, at present, be distinguished by differing antigenic patterns. But this may eventually be possible-for example, by the use of monoclonal antibodies directed against components of myelin found in oligodendrogliomas.

The 10 medulloblastomas tested all expressed glial fibrillary acidic protein and neuroblastic antigen, as recognised by FD19 and UJ181.4 respec- 
Table 2 Reactivity of 164 central nervous system tumours with the monoclonal antibody panel

\begin{tabular}{|c|c|c|c|c|c|c|c|c|}
\hline & No of cases & FD19 & $U J 13 A$ & UJ127.11 & UJ181.4 & LE61 & $2 D 1$ & $A_{2} B_{5}$ \\
\hline Malignant glioma & 31 & + & + & $1^{*}$ & 5 & - & - & + \\
\hline Astrocytoma & 18 & + & + & - & - & - & - & + \\
\hline Oligodendroglioma & 6 & + & + & - & 3 & - & - & + \\
\hline Ependymoma & 14 & + & + & - & - & - & - & + \\
\hline Schwannoma & 10 & - & + & + & - & - & - & + \\
\hline Meningioma & 14 & - & + & - & - & - & - & + \\
\hline Medulloblastoma & 10 & + & + & 8 & + & - & - & + \\
\hline Neuroblastoma & 2 & - & + & + & + & - & - & + \\
\hline Primitive neuroectodermal tumour & 3 & - & + & - & - & - & - & + \\
\hline Choroid plexus tumour & 3 & - & - & - & - & + & - & - \\
\hline Metastatic carcinoma & 41 & - & 5 & - & 1 & 36 & - & 26 \\
\hline Primary brain lymphoma & 9 & - & - & - & - & - & + & - \\
\hline Spinal extradural lymphoma & 3 & - & - & - & - & - & + & - \\
\hline
\end{tabular}

$+=$ all tumours positive; $-=$ all tumours negative.

*Figure denotes the number of tumours positive out of the total of that tumour type.

tively. The pattern of staining was variable in accordance with the degree of glial or neuronal differentiation of individual tumours." Antibody UJ127.11 stained 8/10 medulloblastomas. Central neuroblastomas are rare, but two were encountered in this series: one was situated in the frontal lobe and the other in the nasopharynx (esthesioneuroblastoma). Both lacked glial fibrillary acidic protein and reacted with UJ13A, UJ181.4, and UJ127.11, a pattern similar to that found in a larger series of systemic neuroblastomas. ${ }^{12}$

Schwannomas were characterised by a unique and consistent pattern of reactivity with UJ13A, $\mathrm{UJ} 127.11$, and $\mathrm{A}_{2} \mathrm{~B}_{5}$. Antibody UJ127.11 has previously been widely tested and appears to be a neuronal cell marker ${ }^{3}$ so that this interesting binding pattern confirms the neural crest origin of these tumours.

Metastatic carcinomas in the central nervous system bound antibody LE61 in 36/41 cases. Of the five LE61 negative cases, four reacted with the monoclonal antibody AUA18 (a monoclonal antibody binding to adenocarcinomas, which was generated by $\mathrm{Dr} \mathrm{J}$ Arklie and obtained from $\mathrm{Dr} \mathrm{W}$ Bodmer towards the end of the study). It has now been shown that a combination of LE61 and AUA1 will detect $98 \%$ of cerebral carcinoma metastases (Coakham HB; unpublished observation). The remaining case bound UJ13A and was presumably of bronchogenic origin. Primary bronchogenic tumours of neuroectodermal origin (oat cell carcinomas) bind $\mathrm{UJ}_{13} \mathrm{~A}^{2}$ and, in this series, 5/41 intracranial metastatic carcinomas were shown to have this antigenic profile (Table 2). It is important to note that all the UJ13A positive metastases also contained cytokeratin, thus excluding the possibility that they were primary brain tumours.

Choroid plexus tumours and metastatic carcinomas both bind the monoclonal antibody LE61, but confusion in diagnosis is unlikely in view of their different clinical and radiological features, although histologically there are similarities between the two tumour types. Two of the three choroid plexus tumours examined were poorly differentiated, however, so that initial diagnoses of malignant ependymoma were considered. This difficulty in diagnosis could easily be resolved with the monoclonal antibodies since ependymomas do not bind LE61 (Table 2). Similarly, primitive neuroectodermal tumours are unlikely to be confused with meningiomas despite identical antigenic profiles in the cases reported because they are associated with different clinical and radiological features. Thus meningiomas, unlike primitive neuroectodermal tumours, do not characteristically occur as deep, intrinsic cerebral hemisphere tumours in childhood.

The antibody panel was particularly useful in classifying central nervous system tumours composed of small round cells. Immunohistology was contributory in the diagnosis of 10 cerebral carcinoma metastases $(25 \%)$, two oligodendrogliomas $(33 \%)$, one medulloblastoma $(10 \%)$, two neuroblastomas $(100 \%)$, three primitive neuroectodermal tumours $(100 \%)$, nine brain lymphomas $(100 \%)$, and three spinal extradural lymphomas $(100 \%)$ (Table 3$)$. The brain lymphomas were all $\mathrm{B}$ cell tumours as determined by the binding of monoclonal antibody B1 (Coulter Clone). Immunohistological testing made a substantial contribution to diagnosis in a total of 34 cases $(20.7 \%)$, and in 12 cases, the antibody panel was entirely responsible for the final diagnosis. Some examples are illustrated below.

\section{CASE REPORTS}

\section{Case 1. Anaplastic pineal region tumour}

A 52 year old woman developed acute obstructive hydrocephalus due to a pineal region tumour diagnosed on computed tomogram. The tumour, which was removed via occipital craniotomy, was difficult to classify and was thought to be either a malignant 
Table 3

Made by immunohistology Assisted by immunohistology

\begin{tabular}{lrrr}
\hline Malignant glioma & 31 & 0 & 0 \\
Astrocytoma & 18 & 0 & 0 \\
Oligodendroglioma & 6 & 1 & 1 \\
Ependymoma & 14 & 0 & 0 \\
Schwannoma & 10 & 0 & 0 \\
Meningioma & 14 & 0 & 1 \\
Medulloblastoma & 10 & 0 & 0 \\
Neuroblastoma & 2 & 2 & 2 \\
Primitive neuroectodermal tumour & 3 & 1 & 3 \\
Choroid plexus tumour & 3 & 0 & 8 \\
Metastatic carcinoma & 41 & 2 & 5 \\
Primary brain lymphoma & 9 & 4 & 1 \\
Spinal extradural lymphoma & 3 & 12 & 22 \\
Total & 164 & 2 & \\
\hline
\end{tabular}

Overall contribution of immunohistology: $34 / 164$ cases (20.7\%).

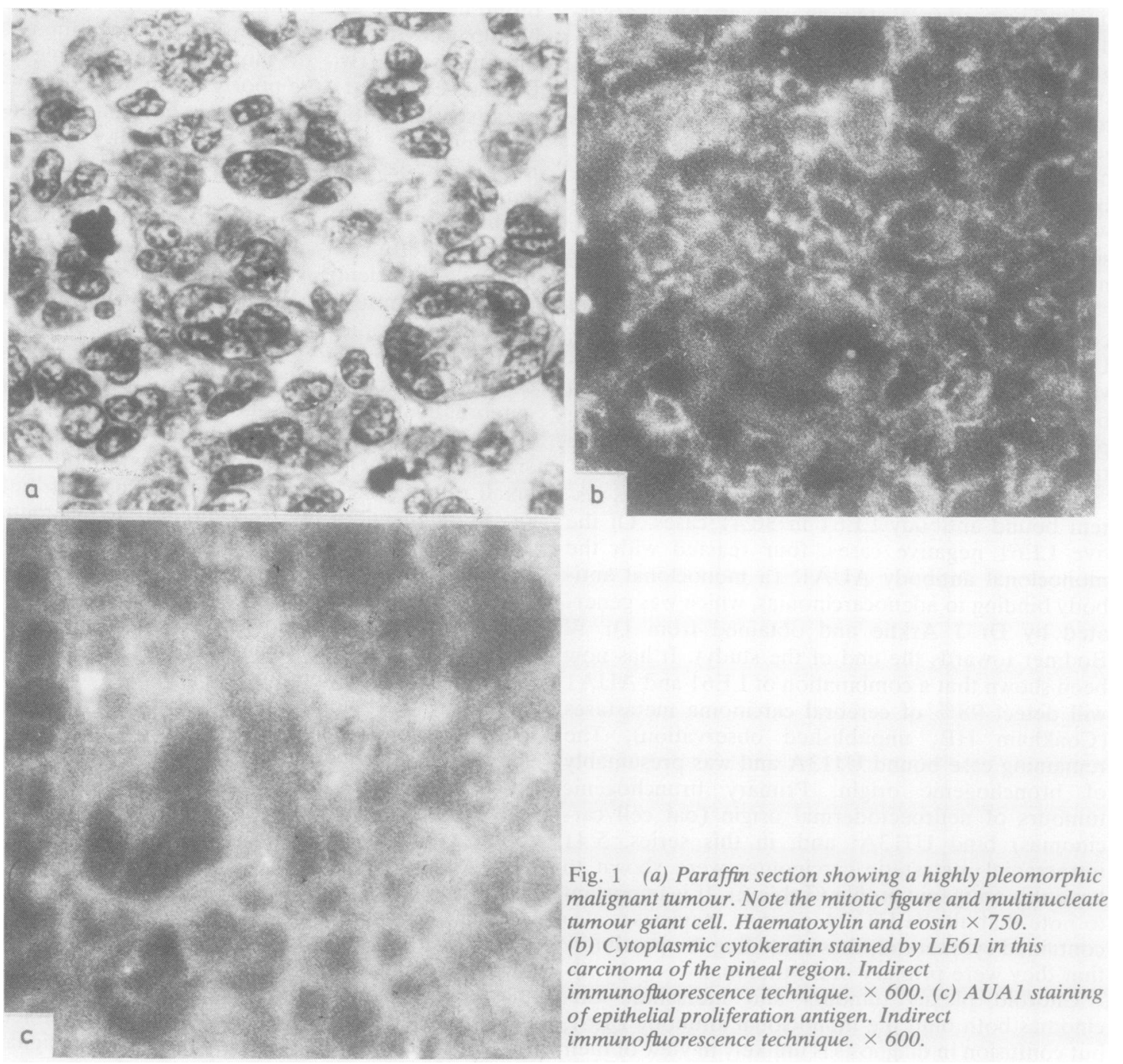

Fig. 1 (a) Paraffin section showing a highly pleomorphic malignant tumour. Note the mitotic figure and multinucleate tumour giant cell. Haematoxylin and eosin $\times 750$. (b) Cytoplasmic cytokeratin stained by LE61 in this immunoftuorescence technique. $\times 600$. 
germ cell neoplasm or an anaplastic secondary carcinoma (Fig. 1a). Binding of antibodies LE61 and AUA1 showed the tumour to be an adenocarcinoma (Fig. 1b, c). This diagnosis was later confirmed by electron microscopy.

\section{Case 2. Small cell nasopharyngeal tumour}

A 10 year old boy developed symptoms related to a nasopharyngeal mass, a biopsy of which showed a small round cell tumour which could not be further classified by routine histological examination. Binding of antibodies UJ13A, $A_{2} B_{5}$, and UJ127.11 excluded lymphoma or germinoma and indicated the tumour to be an olfactory neuroblastoma. Further antibodies, known to react with neuroblastoma cells, also bound to the tumour cells (data not presented). Appropriate neuraxis radiation was given, but the tumour subsequently metastasised into the cerebrospinal fluid, and the same antibodies were used to identify tumour cells in cytospin preparations.

\section{Case 3. Small cell frontal tumour}

An 11 year old girl presented with a large frontal tumour, which was found histologically to be composed of small round cells of undetermined nature (Fig. 2a). Positive immunofluorescence with UJ13A and UJ181.4 showed this to be a primary neuroectodermal tumour with neuroblastic differentiation
(Fig. 2b). Subsequent staining of cultured cells with RT97 (Dr B Anderton) showed $210000 \mathrm{MW}$ neurofilament in cell bodies. This led to the diagnosis of cerebral neuroblastoma, which was later confirmed by electron microscopy. After neuraxis radiation the patient remains well with no evidence of recurrence on computed tomogram or within the cerebrospinal fluid.

\section{Case 4. Lymphoma diagnosed as carcinoma}

A 57 year old woman, who had been treated for spheroidal cell breast carcinoma four years previously, presented with a temporal lobe mass diagnosed on computed tomogram as a probable metastasis. The resected tumour had the histological appearance of an undifferentiated metastasis (Fig. 3a). Uniform immunofluorescence with 2D1 and B1 (Coulter Electronics), however, showed a brain lymphoma of B cell origin (Fig. 3b, c). Radiotherapy is indicated for brain lymphoma and may sometimes produce gratifying remission. However, the patient's condition and the wishes of the family precluded this.

Case 5. Carcinoma diagnosed as probable lymphoma A 70 year old woman presented with gait ataxia. A computed tomogram showed an infiltrative tumour of the cerebellar vermis, which was reported as a possible lymphoma. The macroscopic appearance at

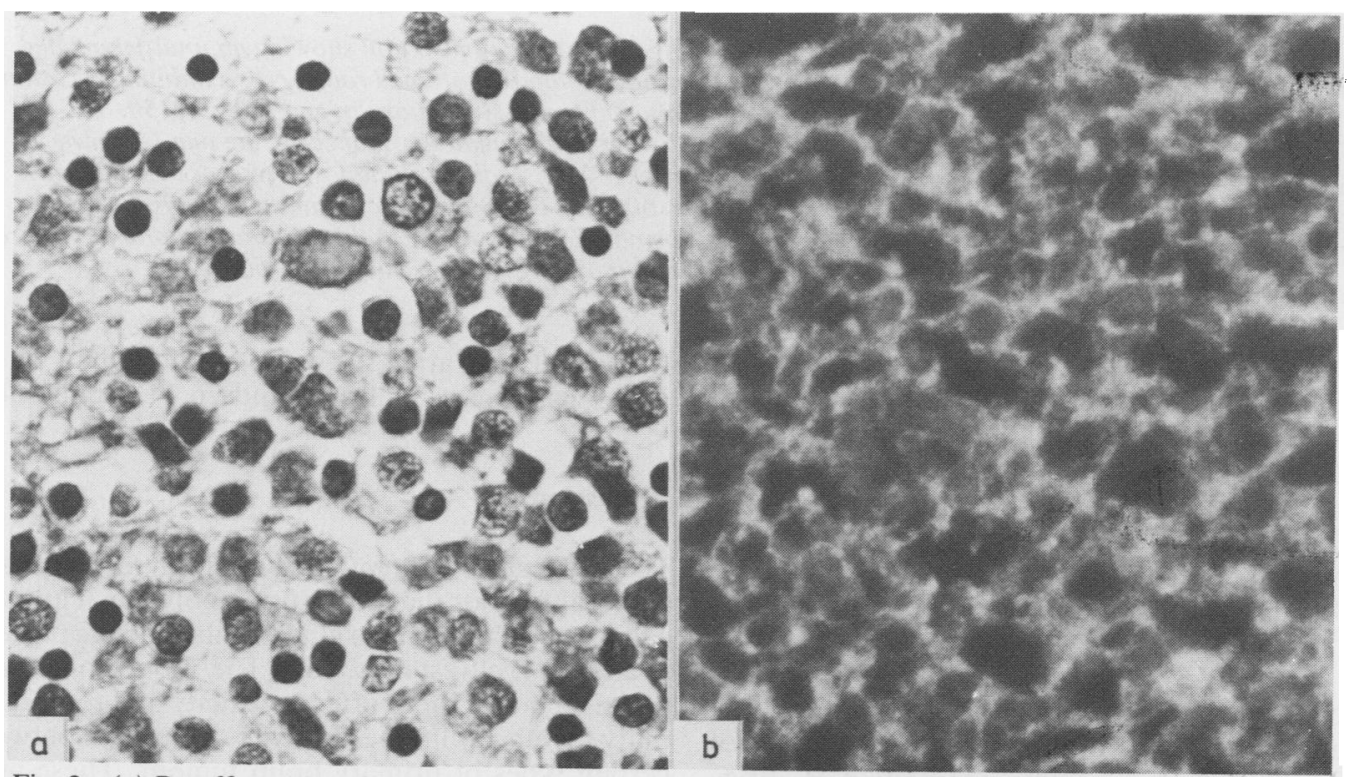

Fig. 2 (a) Paraffin section showing a small round cell tumour of uncertain origin. Haematoxylin and eosin $\times 750$. (b) Cerebral neuroblastoma showing membrane fuorescence when stained by the pan-neuroectodermal marker UJ13A. Indirect immunofuorescence technique. $\times 600$. 


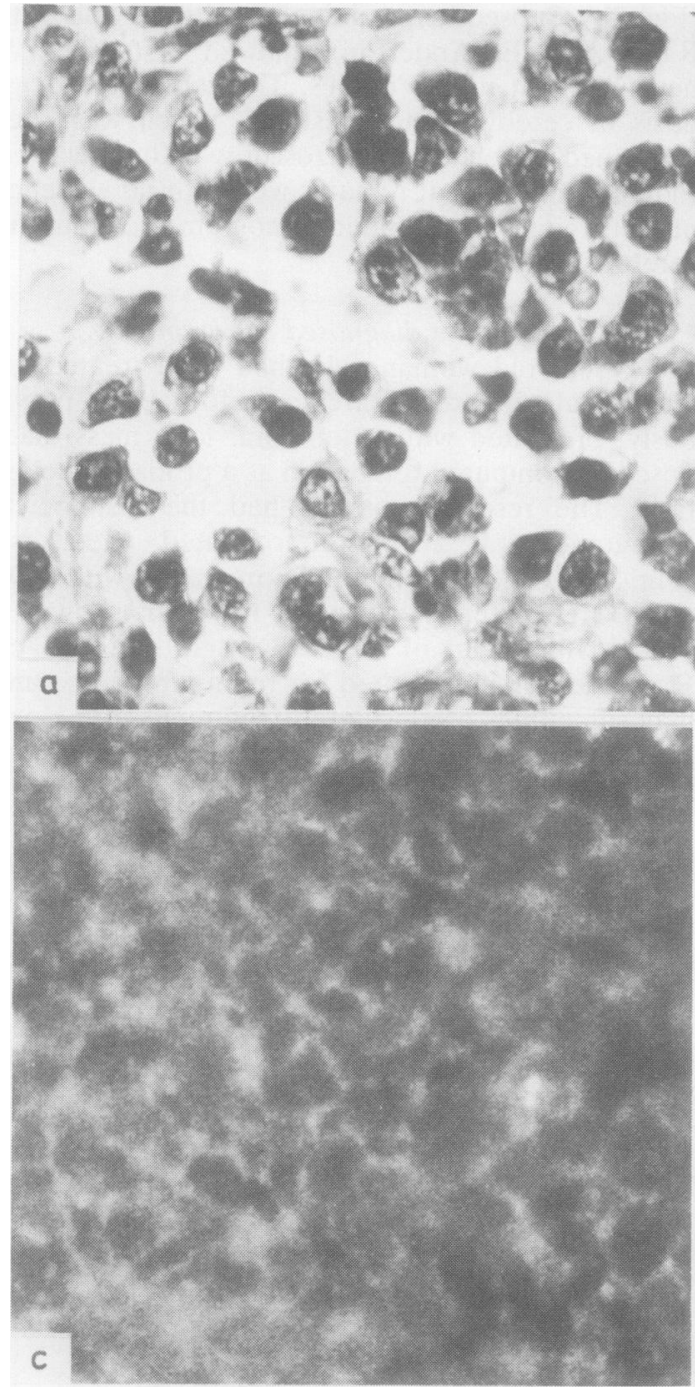

surgery and intraoperative smear preparation supported this diagnosis. Histological sections were also suggestive of lymphoma, although atypical features were noted (Fig. 4a). Immunological testing showed this tumour to be a carcinoma by positive reactivity with LE61 and HMFG1 (Fig. 4b, c). A scanty infiltrate of leucocytes was shown with 2D1 (Fig. 4d). Radiotherapy was not advised in the light of the revised diagnosis.

In addition to this valuable diagnostic information, the study was useful in assessing the specificity of selected reagents: for example, antibody $A_{2} B_{5}$, originally reported as a neuronal marker, ' stained all neuroectodermal tissues whether normal or neoplas-

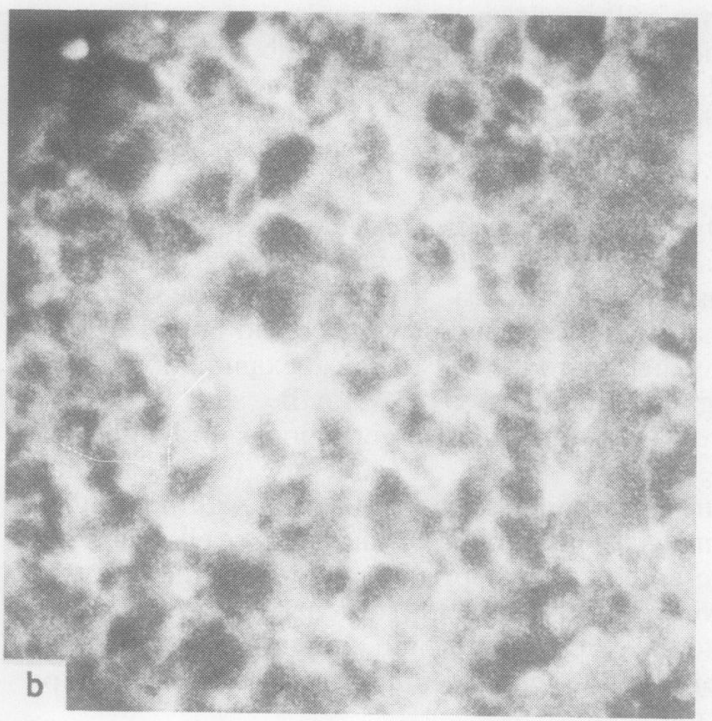

Fig. 3 (a) Paraffin section showing an undifferentiated tumour composed of small round cells exhibiting occasional mitotic figures. Haematoxylin and eosin $\times 750$.

(b) Cerebral lymphoma stained by the pan leucocyte marker 2D1. Indirect immunofluorescence technique. $\times 600$. (c) The B lymphocyte marker $B 1$ producing membrane fluorescence in this cerebral lymphoma. Indirect immunofluorescence technique. $\times 600$.

tic and also stratified squamous epithelium of the upper gastrointestinal tract and 26/41 carcinomas.

\section{Discussion}

The application of immunohistological techniques to cerebral tumour diagnosis, using polyclonal antisera against such antigens as glial fibrillary acidic protein, is already well established. ${ }^{13}$ The monoclonal antibodies reported here offer specificity and reproducibility together with the ability to distinguish between certain types of primary brain tumour. These antibodies are directed against three categories of antigen: (a) oncofetal, tumour associated antigen 


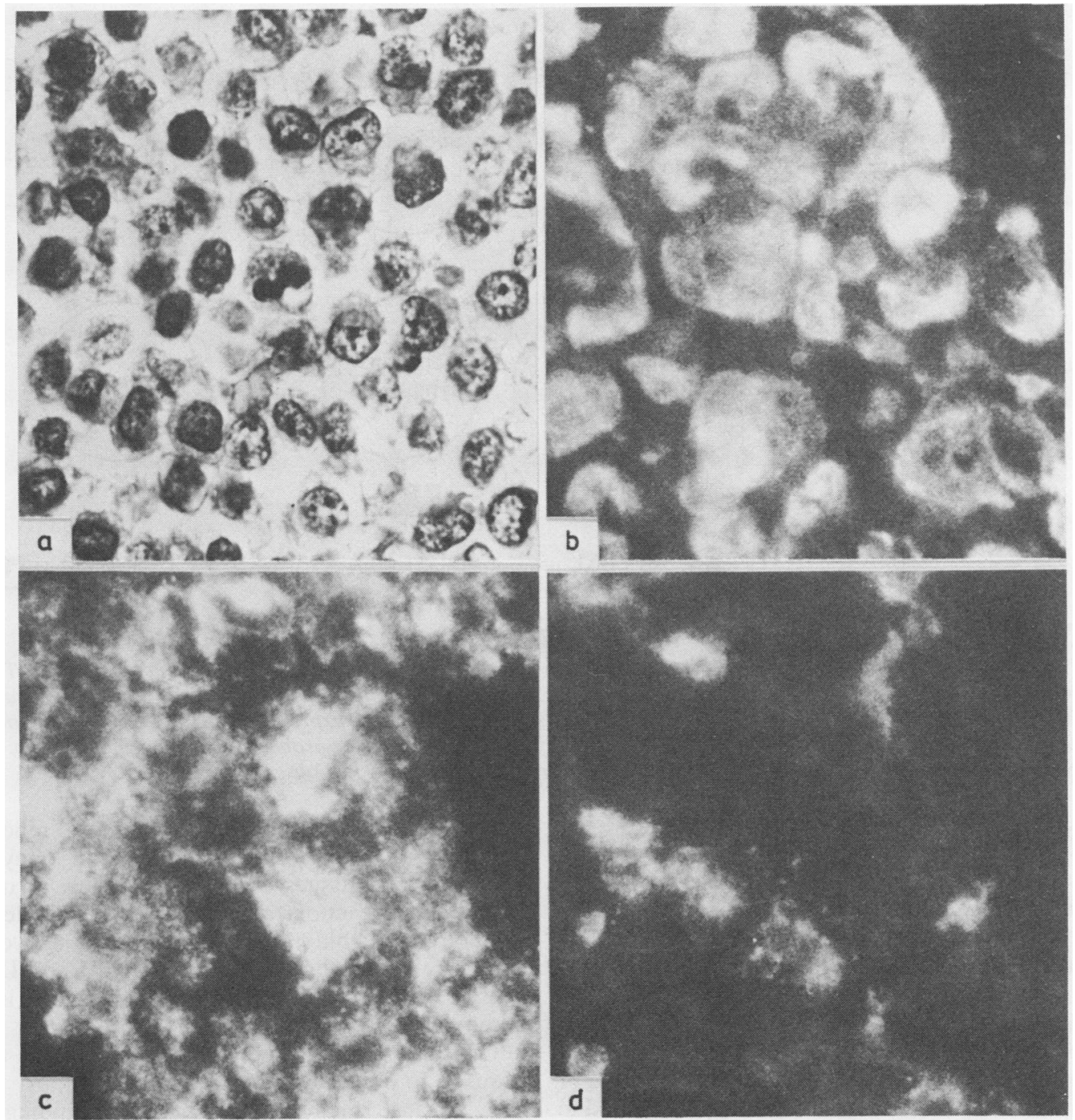

Fig. 4 (a) Paraffin section showing a small round cell tumour originally thought to have lymphocytoid features.

Haematoxylin and eosin $\times 750$. (b) Cytoplasmic fuorescence produced in this carcinoma by the anticytokeratin marker LE61. Indirect immunofuorescence technique. $\times 600$. (c) Monoclonal HMFG1 (antihuman milk fat globule protein ${ }^{24}$ ) staining carcinoma. Indirect immunofuorescence technique. $\times 600$. (d) Scattered infiltrating lymphocytes within this tumour are stained by the pan leucocyte marker 2D1. Indirect immunofuorescence technique. $\times 600$.

(UJ181.4), (b) antigens specific for tissues or germ layers (LE61, 2D1, UJ13A); and (c) differentiation antigens restricted in expression to certain types of neural cells and brain tumours (UJ127.11, FD19).

By using combinations of antibodies it is possible to characterise tumours according to their antigenic profiles (Fig. 5). Tumour diagnosis therefore becomes possible in circumstances where histological clues are missing, particularly $(a)$ when biopsy material is scanty or mechanically deformed; $(b)$ when cells are displaced from their usual anatomical site, as in a metastasis; and (c) when tumours are anaplastic or composed of small round cells. All these problems are encountered in neuropathological practice and require either time consuming and often temperamental special staining techniques or electron microscopy ${ }^{14}$ to obtain a diagnosis of tumour type. Many of the immunohistological diagnoses made with the monoclonal antibodies have later been confirmed by electron microscopy. Anti- 


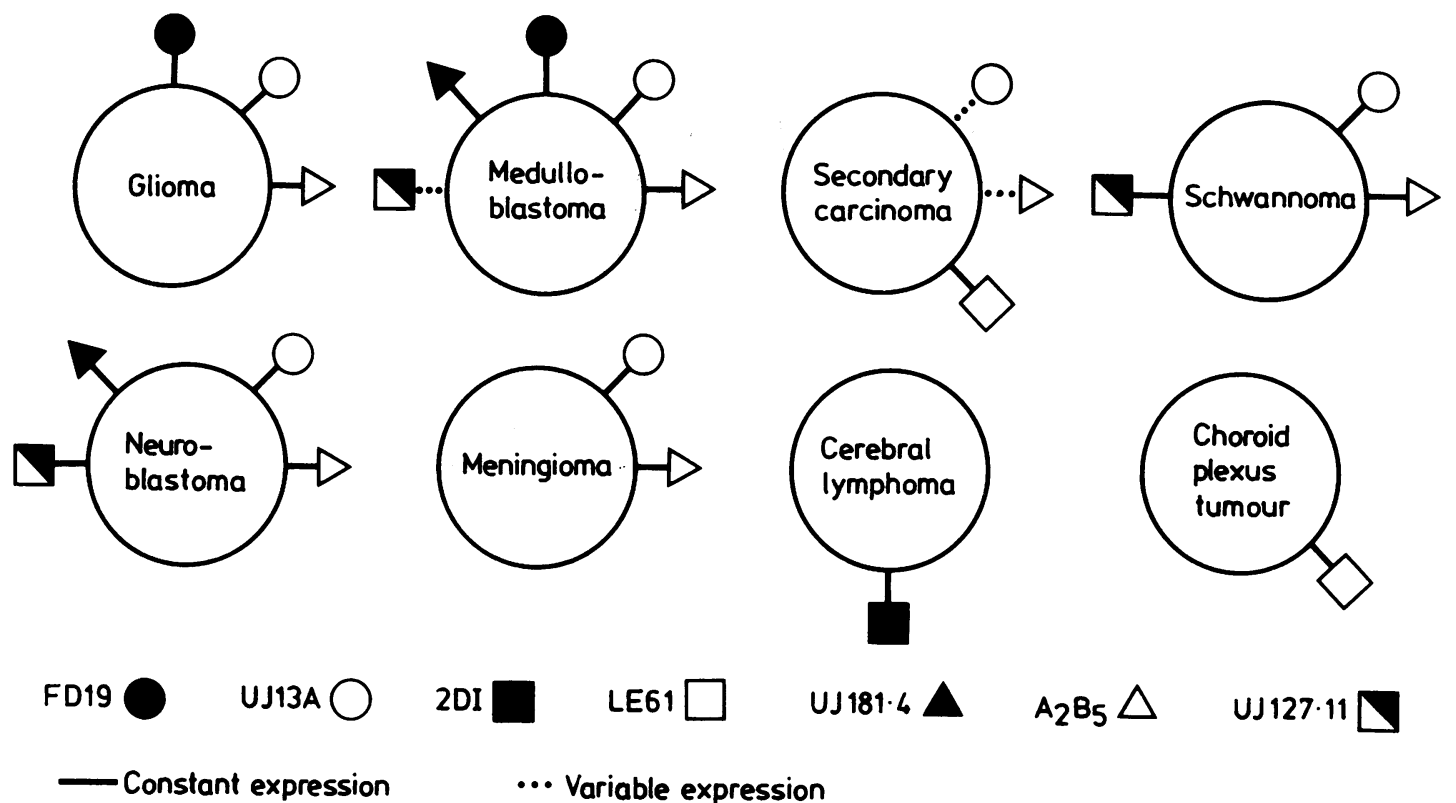

Fig. 5 The antigenic phenotype of eight different cerebral tumours defined by the panel of monoclonal antibodies. This summarises the data obtained from testing 164 tumours. The $A_{2} B_{5}$ antigen was originally thought to be restricted to neuronal cells but appears on all neuroectodermal tumours and some carcinomas. Note the expression of UJ13A antigen by some cerebral metastatic carcinomas. These tumours also expressed cytokeratin and were probably bronchogenic in origin. UJ13A antigen is consistently expressed by small cell lung carcinomas (unpublished observation).

body testing of tumours commends itself, however, on the grounds of cost and time and has less sampling error. The technique can, if necessary, be performed on emergency frozen sections with reduced incubation times to give intraoperative results.

Although heterogeneity in antigen expression by tumour cells of the same type has been previously encountered, ${ }^{12}$ this was found only occasionally in our study and was largely restricted to tumour associated rather than differentiation antigens. For example, of 10 medulloblastomas, only two failed to react with UJ127.11 but bound antibody UJ181.4. Heterogeneity in antigen expression is best understood for malignancies of haemopoietic cells, which are thought to arise from an arrest of differentiation during maturation. ${ }^{15}$ Cells blocked at different points in their maturation express different profiles of intracellular and cell membrane antigens. This may also be the case for intracranial malignancies, although the differentiation pathways concerned in the maturation of neural cells are less clearly understood.

The use of panels of monoclonal antibodies can overcome heterogeneous antigen expression and has already been shown to enhance diagnostic accuracy in general pathological practice. ${ }^{16}$ The value of individual reagents for identifying tumour types has also been reported. ${ }^{17} 18$ Accuracy in diagnosis relies on extensive screening of the antibodies on many different normal tissues and tumour types, as unexpected cross reactions may occur-for example, the antibody $\mathrm{A}_{2} \mathrm{~B}_{5}$ binds to carcinoma cells as well as neural cells and the antibodies UCHT1 and Leu 4 (anti-T cell) also react with Purkinje neurones in the cerebellum. ${ }^{19}$

One prerequisite for the application of this technique is to obtain fresh frozen tumour biopsy samples because many of the antigens binding the monoclonal antibodies are destroyed by formalin fixation and paraffin embedding of the tissues. Once antibodies are characterised in detail on frozen material and their specificities fully understood, however, this should enable them to be used for in vivo targeting to tumours, either diagnostically or therapeutically. ${ }^{20}$ We hope that the panel of antibodies described here will eventually be replaced by similar reagents which react with fixed tissues, bringing the obvious advantages of more widespread clinical application and the ability to examine embedded material retrospectively. Since this study began, at least two such antibodies have been produced which recognise a leucocyte common antigen ${ }^{21}$ and epithelial cytokeratin. ${ }^{22}$

A wide variety of monoclonal antibodies are now 
available as immunohistological markers, and it would clearly be impractical to test tumours routinely with large numbers of antibodies in a random fashion. We suggest that immunohistological diagnosis is best achieved by the use of preselected screening panels such as that described here. When necessary, further characterisation may proceed using appropriate markers. This approach has already proved valuable in immunocytology applied to cerebrospinal fluid. ${ }^{23}$

We are grateful to Drs P Beverley, B Anderton, F Walshe, J Taylor-Papadimitriou, and W Bodmer for generously donating antibodies and to $\mathrm{Dr}$ $\mathrm{G}$ Cole for providing some tumours. Steve Bourne performed the fluorescence photography and Mrs $G$ Wenczek typed the manuscript. This study was supported by the Bristol Brain Cancer Research Fund, the Newman Foundation, the Imperial Cancer Research Fund, and the Medical Research Council. We thank the editor of the Proceedings of the Royal Society of Medicine for permission to reproduce Fig. 5.

\section{References}

' Kohler G, Milstein C. Continuous cultures of fused cells secreting antibody of predefined specificity. Nature 1975; 256:495-7.

2 Allan PM, Garson JA, Harper EI, et al. Biological characterisation and clinical applications of a monoclonal antibody recognising an antigen restricted to neuroectodermal tissues. Int $J$ Cancer 1983;31:591-8.

${ }^{3}$ Kemshead JT, Fritschy J, Garson JA, et al. Monoclonal antibody UJ127.11 detects a 220,000-240,000 MW glycoprotein present on a subset of neuroectodermally derived cells. Int $J$ Cancer 1983;31: 187-95.

4 Garson JA. The development and characterisation of monoclonal antibodies for use in neuropathology. Birmingham: University of Birmingham, 1983. MD Thesis.

${ }^{5}$ Lane EB. Monoclonal antibodies provide specific intramolecular markers for the study of epithelial tonofilament organisation. $J$ Cell Biol 1982;92:665-73.

- Beverley PCL. Production and use of monoclonal antibodies in transplant immunology. Proceedings 11 th international course on transplant and clinical immunology. Amsterdam: Exerpta Medica, 1980:87-94.

' Eisenbarth GS, Walsh FS, Nirenberg M. Monoclonal antibody to a plasma membrane antigen of neurons. Proc Natl Acad Sci 1979;76:4913-7.

${ }^{8}$ Arklie J. Studies of the human epithelial cell surface using monoclonal antibodies. Oxford: University of Oxford, 1981. D Phil Thesis.
- Van der Meulen JDM, Houthoff HJ, Ebels E. Glial fibrillary acidic protein in human gliomas. Neuropathology and Applied Neurobiology 1978;4:177-90.

${ }^{10}$ Velasco ME, Dahl D, Roessmann U, Gambetti P. Immunohistochemical localisation of glial fibrillary acidic protein in human glial neoplasms. Cancer 1980;45:484-94.

" Cammins MB, Cravioto HM, Epstein F, Ransohoff J. Medulloblastoma: an ultrastructural study - evidence for glial and neuronal differentiation. Neurosurgery 1980;6:398-477

${ }^{2}$ Malpas JF, Kemshead JT, Pritchard J, Greaves MF. Heterogeneity in antigenic expression on neuroblastoma cells detected by monoclonal antibodies. In: Paediatric oncology: Proceedings of IXVth meeting of the International Society of Paediatric Oncology, 1982. Amsterdam: Exerpta Medica, 90-5.

${ }^{13}$ Bignami A, Eng LF, Dahl D, Uyeda CT. Localisation of glial fibrillary acidic protein in astrocytes by immunofluorescence. Brain Res 1972;43:429-35.

14 Ghadially FN. The role of electron microscopy in the determination of tumour histogenesis. Diagnostic Histopathology $1981 ; 4: 245-62$.

is Greaves MF, Janossy G, Francis G, Minowada J. In: Differentiation of normal and neoplastic haemopoietic cells. New York: Cold Spring Harbour Lab, 1978:827-41.

16 Gatter KC, Abdulaziz K, Beverley PCL, et al. Use of monoclonal antibodies for the histopathological diagnosis of human malig nancy. J Clin Pathol 1982;35:1253-67.

17 Pizzolo G, Sloan J, Beverley PCL, et al. Differential diagnosis of malignant lymphoma and non-lymphoid tumours using monoclonal anti-leukocyte antibody. Cancer 1980;46:2460-7.

18 Trojanowski JQ, Lee VM-Y. Monoclonal and polyclonal antibodies against neural antigens: Diagnostic applications for studies of central and peripheral nervous system tumours. Human Pathol 1983;14:281-5.

${ }^{14}$ Garson JA, Beverley PCL, Coakham HB, Harper EI. Monoclonal antibodies against human $\mathrm{T}$ lymphocytes label Purkinje neurones of many species. Nature 1982;298:375-7.

${ }^{20}$ Kemshead JT, Jones DH, Goldman A, Richardson RB, Coakham HB. Is there a role for radioimmunolocalisation in the diagnosis of intracranial malignancies? J Roy Soc Med 1984;77:847-54.

21 Warnke RA, Gatter KC, Falini B, et al. Diagnosis of human lymphoma with monoclonal antileucocyte antibodies. $N$ Engl J Med 1984;309: 1275-81.

${ }^{22}$ Makin CA, Borrow LG, Bodmer WF. A monoclonal antibody to cytokeratin for use in routine histopathology. J Clin Pathol 1984;37:975-83.

${ }^{23}$ Coakham HB, Garson JA, Brownell B, et al. The use of a monoclonal antibody panel to identify malignant cells in cerebrospinal fluid. Lancet 1984;i: 1095-7.

24 Arklie J, Taylor-Papadimitriou J, Bodmer WF, Egan M, Millis R. Differentiating antigens expressed by epithelial cells in the lactating breast are also detectable in breast cancers. Int $J$ Cancer 1981;28:23-9.

Requests for reprints to: Mr HB Coakham, Department of Neurological Surgery, Frenchay Hospital, Bristol BS16 1LE, England. 